Age-Specific Costs of First-Time Breeding

Author(s): Anne Viallefont, Fred Cooke, Jean-Dominique Lebreton

Reviewed work(s):

Source: The Auk, Vol. 112, No. 1 (Jan., 1995), pp. 67-76

Published by: University of California Press on behalf of the American Ornithologists' Union

Stable URL: http://www.jstor.org/stable/4088767

Accessed: 17/02/2012 18:56

Your use of the JSTOR archive indicates your acceptance of the Terms \& Conditions of Use, available at http://www.jstor.org/page/info/about/policies/terms.jsp

JSTOR is a not-for-profit service that helps scholars, researchers, and students discover, use, and build upon a wide range of content in a trusted digital archive. We use information technology and tools to increase productivity and facilitate new forms of scholarship. For more information about JSTOR, please contact support@jstor.org. 


\title{
AGE-SPECIFIC COSTS OF FIRST-TIME BREEDING
}

\author{
ANNE Viallefont, Fred COOKE ${ }^{1}$, AND JEAN-DOMiniQue Lebreton \\ C.E.F.E./C.N.R.S., B.P. 5051, 34033 Montpellier cedex, France
}

\begin{abstract}
We investigated the cost of first-time breeding in a population of Lesser Snow Geese (Anser caerulescens caerulescens) nesting at La Perouse Bay, Manitoba, Canada. We estimated local survival and capture probabilities of female geese by capture-recapture analysis. We first found that birds were less likely to be recaptured one year after their first successful breeding than on later occasions. Since only successfully nesting birds are captured, this suggests that first-time breeding affects the ability of nesting the next year. We then show that this effect of first breeding is much more severe for birds nesting at age 2 (the youngest age at which Lesser Snow Geese can breed) than for birds starting to breed at an older age. Finally, we compare the mean expected lifetime reproductive success for birds breeding for the first time as two-year-olds or as three-year-olds, conditionally on their survival until age 4. On average, birds first nesting as two-year-olds produce similar numbers of offspring in a lifetime as birds starting at age 3. Received 28 July 1993, accepted 11 January 1994.
\end{abstract}

ASSESSING THE COSTS of reproduction is one of the key challenges of applying life-history theory to natural populations. There are two major questions: (1) Does present reproductive effort have an adverse effect on future life history (survival or reproductive performance)? (2) Do relative costs of reproduction vary among different segments of the population?

Empirical answers to the first question are extremely difficult to obtain in the field. Although life-history theory predicts some genotypic trade-offs between early and late reproduction (Williams 1966), negative phenotypic trade-offs are not necessarily expected, since environmental factors can induce positive covariation among individuals for several components of fitness (Reznick 1985, Van Noordwijk and de Jong 1986). As a consequence, whereas a negative phenotypic covariance among life-history traits is evidence for such trade-offs, results showing no or positive covariance are not evidence against (Nur 1990). Many researchers, therefore, have concluded that experimentation is necessary to investigate the costs of reproduction (e.g. Gustafsson 1990). However, to investigate differences in overall fitness among individuals or groups within a population, there is no substitute for detailed measures of components of fitness under field conditions. Such studies are essential for a bet-

\footnotetext{
${ }^{1}$ Present address: Department of Biological Sciences, Simon Fraser University, Burnaby, British Columbia V5A 1S6, Canada.
}

ter understanding of the selective pressures in natural populations.

In highly philopatric species, birds often are absent from the nesting area in the year following their first observed successful breeding (Wooller and Coulson 1977, Ollason and Dunnet 1988, Weimerskirch 1990). This suggests that the first breeding experience is more costly than those in subsequent years. If this is the case, we might expect the cost of first-time breeding to vary with the age of first breeding. A second question is whether the cost of first-time breeding is a function of age per se or of the breeding event itself (i.e. do birds fail more frequently after their first successful attempt because they were young, or because they bred successfully relative to birds of same age that did not breed?).

Newton (1988) found no differences in lifetime reproductive success among female Sparrowhawks (Accipiter nisus) that had bred for the first time at one, two, or three years of age. He reasoned that, because of the risk of mortality, it is advantageous for the birds to begin reproduction as early in life as possible, even if breeding performance in the early years is poor. He attributed variation in age of first reproduction to variation in quality among individuals, such that only good-quality birds would be able to breed at the youngest ages. He concluded that delayed maturation was a result of environmental conditions (the "constraint" hypothesis) rather than of life-history trade-offs (the "restraint" hypothesis; Curio 1983). However, the lifetime-reproductive-success calculations used by Newton (1988) are only valid if resighting probabilities are close to $100 \%$. 
With the recent development of statistical models for capture-mark-recapture data, it is now possible to investigate variation in survival and breeding propensity with capture rates lower than $100 \%$. These models are generalizations of the Cormack-Jolly-Seber model (e.g. Lebreton et al. 1992). They enable one to discriminate between survival (more accurately survival in area where marking and recapturing occurs; this we will refer to as local survival, noted $\phi$ ) and recapture (noted $p$ ) probabilities. These developments have resulted in computer programs such as SURGE (Pradel et al. 1990), and RELEASE (Burnham et al. 1987; for review, see Lebreton et al. 1993), and provides the evolutionary biologist with new tools to investigate life-history parameters.

We address here the question of variability in age of first breeding in a species that has delayed maturation. Cooke and Rockwell (1988) showed that in the population of Lesser Snow Geese (Anser caerulescens caerulescens) nesting at La Perouse Bay, Manitoba, no one-year-olds, about $50 \%$ of two-year-olds, and about $86 \%$ of three-year-olds bred. Some birds delay breeding until at least four years of age.

We examine the consequences of first-time breeding on both local survival and future reproductive success. We pose three questions: (1) Do Lesser Snow Geese have lower local survival and/or breeding success in the year following their first breeding year than after later breeding occasions? (2) If there is greater cost to first breeding than to later breeding, does this vary with the age of first breeding? (3) For the youngest birds, do those that breed incur a greater cost in terms of later breeding than those that do not breed? We then are able more accurately to discriminate between the restraint and the constraint hypotheses. We roughly calculate the overall fitness consequences of first breeding at two versus three years of age in order to ascertain which, if either, is the more productive tactic.

\section{MethODS}

Data collection.-Our analysis is based on the longterm study of a nesting population of Lesser Snow Geese at La Perouse Bay, Manitoba, Canada. The population has expanded from about 2,000 nesting pairs in 1969 to more than 15,000 pairs in 1990 . Between 1,500 and 7,000 birds, both adults and young, have been banded each year since 1969 . On average about
$25 \%$ of the population of living marked birds are recaptured each year. For this analysis we used only those birds banded as goslings, that recruited into the breeding population, and were caught in the annual banding drives at least once as adults. Females only were used because they are highly philopatric to their natal nesting area, whereas males are not (Cooke et al. 1975). Our sample consisted of 2,616 birds.

Banding drives are carried out annually in the traditional brood-rearing areas around La Perouse Bay using the mass-banding techniques described by Cooke (1987). Birds are usually banded around the end of July or early August, when adults are completing their annual remigial molt and young birds are around 35 days of age and close to fledging. All birds are banded with a Monel Canadian Wildlife Service band and an individually identifiable color band. Rarely, birds banded as young are caught as nonbreeding yearlings. These records were removed from the capture-mark-recapture data in our study since we are concerned with the breeding history of the individuals. Earlier work has shown that, with rare exceptions, adults caught in the banding drives are breeding adults, successful at least to the time at which goslings leave the nest. Nonbreeders, prebreeders, and failed breeders leave the area during the period of hatch and molt at least $100 \mathrm{~km}$ to the north (Abraham 1980). Therefore, we can assume that, for any given year, the differences in capture rates of birds of different categories reflect differences in the probabilities of breeding among these categories.

Modeling capture-mark-recapture data.-Data were organized into capture-history arrays (Burnham et al. 1987). Since we were interested only in the adult lives of these birds banded as goslings, we modified the capture-history arrays by discounting the first capture (as goslings; Clobert et al. 1994). Thus, our data consist entirely of capture histories of female recruits of known age. In addition, these data can be split into subsets, according to the age at which the birds were first recaptured as breeding adults. This is not necessarily the age of first breeding, since only about $25 \%$ of birds are recaptured annually, and a bird may have evaded recapture prior to the first occasion when we record its breeding.

These data were then analysed using programs RELEASE and SURGE, which enabled us to test the goodness-of-fit of a global model involving both a time effect $(t)$ and a "first-breeding" effect $(F)$ on survival and recapture rates. The time effect assumes that these rates may vary across years, and the first-breeding effect assumes that survival and recapture rates of birds that have been caught for the first time the preceding year differ from those of birds that had been seen before the preceding year. Therefore, there are two classes of parameters to estimate under this model: (1) those (survival and capture) concerning the year following the first breeding; and (2) those concerning all subsequent recapture occasions. This 
global model is noted $\left(\phi_{t \cdot F}, p_{t \cdot F}\right)$, using the notation proposed by Lebreton et al. (1992) for capture-markrecapture models; $\phi$ represents the survival rates, $p$ the recapture rates, $F$ the first-breeding effect, and $t$ the annual variation. The goodness-of-fit test for this global model was not immediately provided by any software; therefore, the original way in which we used RELEASE and SURGE for this study is described in the Appendix.

Simpler models were then fitted with the SURGE program, which calculated for each of them the deviance of the data to the model and the maximumlikelihood estimates of survival and capture rates. These various models were constructed by stepwise elimination of different factors and/or interaction between them in order to find a model that explains the variation in the data using the minimum number of parameters (i.e. a parsimonious model). Model selection was based on the minimization of Akaike's information criterion (AIC), as recommended by Lebreton et al. (1992). This method leads to the bestfitting parsimonious model. Further tests were based on likelihood-ratio tests.

For this study we used a modified version of the SURGE program, which allowed us to calculate directly the relative proportions of captured birds of each class (second-time breeders or experienced birds) using a logarithmic link function. We first fitted these models to the whole data set of female recruits. Next we subdivided the data into two parts, one containing only birds recaptured for the first time as two-yearold breeders, and the rest. The former must have been first-time breeders, but the latter contain first-time breeders, as well as birds that may have escaped detection prior to their first detected recapture. We performed the analyses separately on these two subsets. Finally, we examined birds first recaptured as threeyear-olds. As we show later, most three-year-olds in our sample are also first-time breeders.

Lifetime-reproductive-success calculations. -We estimated the expected production of young during the first four years of life for birds breeding for the first time as two- or three-year-olds. The variation in production of young before age 4 accounts for variation in lifetime reproductive success if expected survival and fecundity beyond age 4 are independent of age and breeding experience.

Rockwell et al. (1993) have calculated age-specific components of fecundity of Lesser Snow Geese. From these we could estimate the relative success of birds which nest successfully for the first time at either two or three years of age. For this estimation, we made the following assumptions: (1) Fledging success is a good measure of age-specific fecundity (i.e. postfledging survival to recruitment is independent of parental age). Rockwell et al. (1993) showed this to be true for this population of Lesser Snow Geese. (2) Survival of two-year-old and older birds is independent of age and breeding experience. Francis et al. (1993) and our study provide evidence for this assumption. (3) The mean fecundity of first- or second-time breeding threeyear-olds is the same. Cooke et al. (1981) showed this to be true at least for clutch size, and more recent (unpublished) data confirm this conclusion. (4) The cost of first breeding does not affect the breeding probability two or more years later (which would appear in our study as a lack of fit of the global model presented above).

Therefore, for birds nesting successfully as twoyear-olds, we calculated the average number of young produced during the first four years of life as:

$$
\begin{aligned}
N(2)= & n(2)+\operatorname{Pr}(B 3 / B 2) \cdot n(3) \\
& +\operatorname{Pr}(B 4 / B 2) \cdot n(4),
\end{aligned}
$$

where $n(x)$ is the average number of fledgings produced by an $x$-year-old bird (calculated from data of Rockwell et al. 1993), and $\operatorname{Pr}(B y / B x)$ is the probability for a bird to breed successfully at age $y$, knowing that it bred successfully for the first time at age $x$. In the calculation of $n(x)$, we did not take account of birds abandoning the nest before hatching, since we know that these are not captured. According to assumption 4, we assume that $\operatorname{Pr}(B 4 / B 2)$ is 1 .

Similarly, for birds nesting successfully for the first time as three-year-olds, we obtain:

$$
N(3)=n(3)+\operatorname{Pr}(B 4 / B 3) \cdot n(4) \text {. }
$$

Asymptotic estimates of the standard errors of $N(2)$ and $N(3)$ and the $\operatorname{COV}(N(2), N(3))$ were obtained by the delta method (i.e. by linearization of corresponding formula; see Seber 1982:7-9).

\section{RESULTS}

Modeling capture-mark-recapture data.-The first model fitted included both time dependence and first-breeding effect on both local survival and capture rates. This model is noted $\phi_{t * F}, p_{t * F}$. This model fit the data $(P \approx 0.74$; see Appendix) and, therefore, could be used as a global model for further investigation.

Simpler models were then tested for both local survival $\phi$ and recapture $p$ (Table 1 ). The best model in terms of AIC, among those fitted, was $\left(\phi, p_{t+F}\right)$. The constant $\phi$ term indicates that there was no significant time or first-breeding effect on the annual local survival rate. The estimated annual survival probability is 0.714 (95\% confidence interval 0.697-0.730). By contrast, the capture probability $\left(p_{t+F}\right)$ was affected by both a yearly effect, and a first-breeding effect. Figure $1 \mathrm{~A}$ shows the estimates of recapture probabilities under model $\left(\phi, p_{t \cdot F}\right)$, which allows yearspecific recapture probabilities to be estimated independently for each class (first or experi- 
TABLE 1. Results of various capture-recapture models (overall data), including deviance (DEV), number of estimable parameters (np), and AIC for each. Best model (i.e. giving lowest value of AIC) is $\phi, p_{t+F}$, which incorporates constant survival, as well as additive effects of time and first breeding on recapture probability.

\begin{tabular}{llccccc}
\hline \hline \multirow{2}{*}{$\begin{array}{c}\text { Survival } \\
\text { model }\end{array}$} & & \multicolumn{5}{c}{ Recapture model } \\
\cline { 2 - 7 }$\Phi_{t \cdot F}$ & DEV & $p_{t \cdot F}$ & $p_{t+F}$ & $p_{t}$ & $p_{F}$ & $p$ \\
& np & $8,594.66$ & $8,617.42$ & $8,630.34$ & $8,656.74$ & $8,665.97$ \\
& AIC & $\mathbf{7 2}$ & 56 & 55 & 39 & 38 \\
$\Phi_{t+F}$ & DEV & $8,609.95$ & $8,635.85$ & $8,650.19$ & $8,734.74$ & $8,741.97$ \\
& np & 56 & 39 & 38 & 22 & $8,705.35$ \\
& AIC & $8,721.95$ & $8,713.85$ & $8,726.19$ & $8,739.86$ & $8,747.35$ \\
$\Phi_{t}$ & DEV & $8,609.96$ & $8,633.32$ & $8,654.22$ & $8,697.19$ & $8,712.07$ \\
& np & 55 & 38 & 37 & 21 & 20 \\
& AIC & $8,719.96$ & $8,709.32$ & $8,728.22$ & $8,739.19$ & $8,752.07$ \\
$\Phi_{F}$ & DEV & $8,631.89$ & $8,661.54$ & $8,677.09$ & $8,727.57$ & $8,739.62$ \\
& np & 39 & 22 & 21 & 4 & 3 \\
& AIC & $8,709.89$ & $8,705.54$ & $8,719.09$ & $8,735.57$ & $8,745.62$ \\
& DEV & $8,631.94$ & $8,662.02$ & $8,681.44$ & $8,727.59$ & $8,741.37$
\end{tabular}

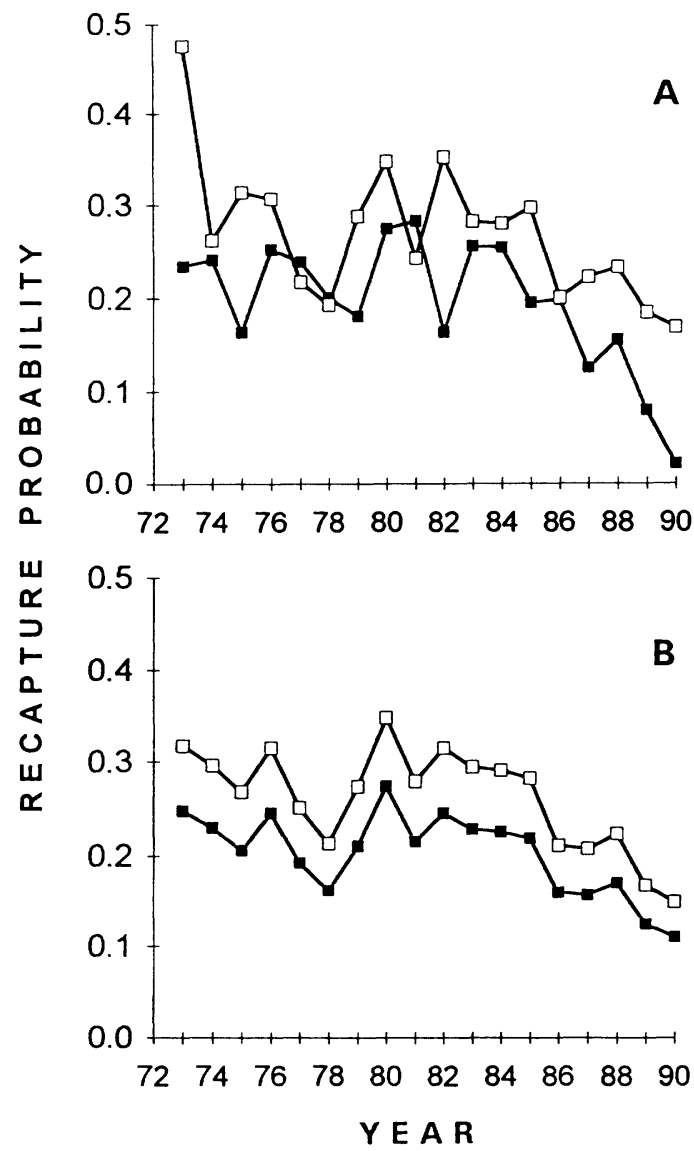

Fig. 1. Estimates of recapture rates after first breeding $(\square)$ or after later recapture occasions $(\square)$ under (A) model $\phi_{t}, p_{t \cdot F}$ and (B) model $\phi_{t}, p_{t+F}$ for all birds. enced breeders). Figure 1B shows the estimates of recapture probabilities under model $\left(\phi, p_{t+F}\right)$, which eliminates the interaction term between time and first breeding. The latter is the best model in terms of AIC. Birds of both classes (first-time or later breeders) can then be considered as affected by annual variation in the same way.

The annual variation in recapture rates reflects mainly the annual variation in the effort expended on the banding drives each year. The first-breeding effect is the more interesting biologically; it shows that birds breeding for the first time are $22.8 \%$ (95\% confidence interval $13.3-31.3 \%$ ) less likely to be recaptured in the following year than on later attempts. Although other interpretations are possible (see Discussion), we interpret this lower recapture rate as evidence of a lower probability of breeding successfully the year after the first observed successful breeding.

For birds having bred for the first time as twoyear-olds, the preferred model also was $\left(\phi, p_{t+F}\right)$. These birds have a recapture probability in the year after first nesting $45.2 \%$ (95\% confidence interval 30.2-56.9\%) lower than on subsequent occasions (Fig. 2). The analysis of the subset containing birds recaptured for the first time at an older age also lead to the model $\left(\phi, p_{t+F}\right)$, but these birds showed a much lower reduction in recapture probability (ca. $15.6 \% ; 95 \%$ confidence interval 3.6-26.1\%; Fig. 3). There were no differences in local survival probabilities either 


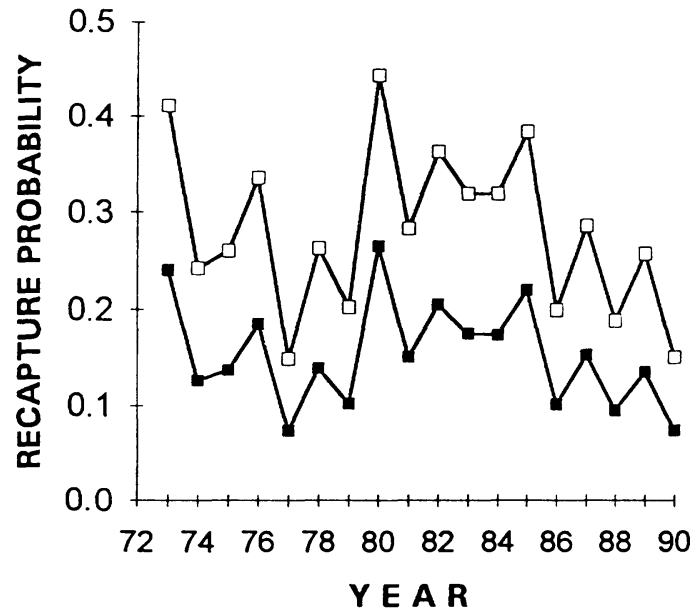

Fig. 2. Estimates of recapture rates after first breeding ( $\square$ ) or after later recapture occasions ( $\square$ ) under model $\phi_{t}, p_{t+F}$ for birds first recaptured as twoyear-old breeders.

between the first and later recaptures of each group, or between groups.

As for the birds recaptured for the first time as three-year-olds, we can roughly estimate how many of them were actually first-time breeders. Of 870 birds caught as three-year-olds, only 78 had been caught the year before (as two-yearold breeders). Knowing that the overall capture probability in this population is about 0.237 (95\% confidence interval 0.221-0.253), we can assume that these 78 birds represent about $23.7 \%$ of the actual number of birds having bred at age 2 among the birds captured at age 3 . Thus, we expect that $78 / 0.237$, or about 329 birds of the total three-year-olds had bred successfully as two-year-olds. From this we calculate that about $870-329=541$ of the 792 birds first captured as three-year-olds were first-time breeders. This represents about $68.3 \%$ of the sample. Most three-year-olds in our sample, therefore, are first-time breeders. The data show no evidence of reduced local survival or recapture after first recapture for such birds. Even though there is some dilution of the effect because of contamination of this sample by some second-time breeders, it is clear that the effect of first-time breeding on three-year-olds is much less than the effect on two-year-olds.

This conclusion leads to the question whether this cost is an effect of age per se rather than an effect of breeding. We now examine whether it is more costly in terms of future reproductive success for a two-year-old bird to breed suc-

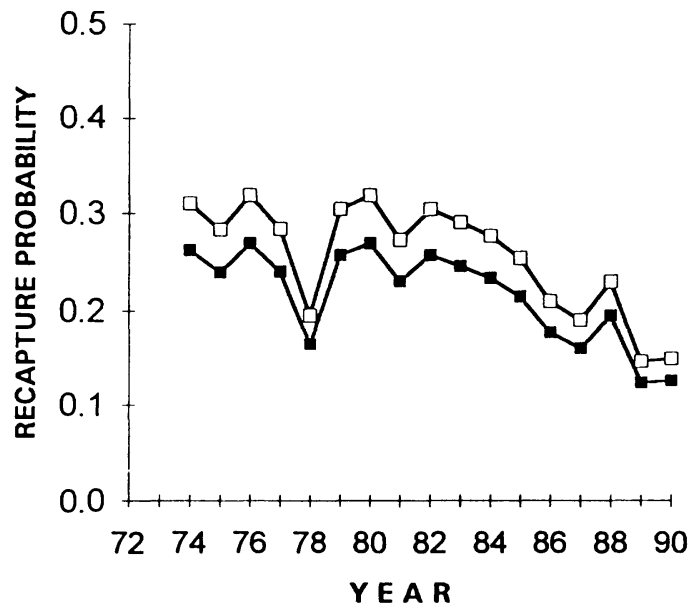

Fig. 3. Estimates of recapture rates after first breeding $(\square)$ or after later recapture occasions ( $\square$ ) under model $\phi_{t}, p_{t+F}$ for birds first recaptured at age greater than two years.

cessfully than not to breed successfully. If there was an equal cost of nonbreeding than of breeding at age 2, we would expect $54.8 \%$ (95\% confidence interval 43.1-69.8\%) of all three-yearold birds to breed each year. Cooke and Rockwell (1988) estimated that around $86 \%$ of three-year-old birds bred successfully, relative to the proportion of older successful breeding adults. This suggests that successfully nesting two-year-olds are less represented among successful three-year-olds than nonbreeding or unsuccessfully breeding two-year-olds.

Lifetime-reproductive-success calculations. - From the original data of Rockwell et al. (1993), we obtained the values: $n(2)=1.62 \pm \mathrm{SE}$ of 0.85 ; $n(3)=2.01 \pm 0.81 ;$ and $n(4)=2.40 \pm 0.73$. From the results above we obtained a $\operatorname{Pr}(B 3 / B 2)$ of $0.55 \pm 0.07$ for two-year-old breeders, and a $\operatorname{Pr}(B 4 / B 3)$ of $0.84 \pm 0.06$ for three-year-old or older breeders. It is assumed that $\operatorname{Pr}(B 4 / B 2)$ is 1 (see Methods).

The estimation of the average number of young produced during the first four years of life is then an $N(2)$ of $5.13 \pm 1.21$ for birds starting to breed as two-year-olds, and an N(3) of $4.05 \pm 1.02$ for birds starting as three-yearolds; the $\operatorname{COV}(N(2), N(3))$ is 0.80 . This difference is not significant (Wald test, $P \approx 0.256$ ). Because of their reduced probability of nesting successfully the next year, birds that start breeding as two-year-olds do not have a significantly higher expected production of goslings than birds that start breeding as three-year-olds. 


\section{Discussion}

We have been able to test for variation in both local survival and recapture probabilities in relationship to time, breeding experience, and age at first breeding. The models that best fit our data (in terms of AIC) are those showing $\phi$ (local survival) to be a constant. There is no evidence for variation in local survival with annual conditions during the 20 years of the study for this sample of birds. Local survival also did not depend on whether the birds had been observed breeding for the first time or on later occasions, nor on the age of first-observed breeding. Our estimate of local annual survival for adult females is 0.714 , which is consistent with other studies of this population of Lesser Snow Geese (e.g. Francis and Cooke 1993).

In contrast to local survival, recapture rates vary with time and according to the detected breeding experience of the birds. Variation in time is probably not biologically interesting, since it primarily reflects the variation in effort that has been put into the banding operations during the study (mainly determined by availability of research funds) and also because the population has increased over time (Cooch et al. 1989).

We found that birds seen breeding for the first time are less likely to be recaptured one year later than those seen breeding on a second or subsequent occasion. A lower recapture frequency of first-time detected breeders probably reflects temporary emigration rather than some type of temporary trap shyness. As mentioned above, the banding drives catch overwhelmingly birds that have bred successfully (Cooke and Rockwell 1988). Thus, the most likely reason for temporary noncatchability is either because birds do not breed or because they fail early in the nesting attempt. An alternative suggestion is that birds may nest successfully, but be more likely to move to a more remote broodrearing area after the first nesting occasion. This could occur, for example, if young birds were more likely to change nest sites and, as a result, be closer to different brood rearing areas. Yet, it seems unlikely that they subsequently would return to the initial brood-rearing area when they age. If young birds were less philopatric, we would expect it to be reflected in permanent not temporary emigration. The former would be confounded in the models with survival rather than recapture.
Therefore, our data strongly suggest that birds are less likely to reproduce successfully in the year following their first successful breeding. This reflects a considerable cost to reproduction and no doubt influences the lifetime reproductive success. On average, first-time detected breeders have a $77 \%$ probability of being recaptured the next year, relative to later breeders. This value is almost certainly an overestimate since we do not necessarily capture a bird on its first successful nesting occasion and some of the first-time detected breeders undoubtedly have nested undetected in years prior to the first time they appear in our recapture sample. The finding of lower breeding probability in the year after the first successful breeding is not new in birds, but its detection in earlier examples has been restricted to species where recapture rates are virtually $100 \%$, such as highly philopatric colonial seabirds. Wooller and Coulson (1977) found that $27 \%$ of female Blacklegged Kittiwakes (Rissa tridactyla) failed to appear in the year following the first breeding attempt. A comparable figure for older breeding females was $5 \%$. Weimerskirch (1990) found that first-time breeding Antarctic Fulmars (Fulmarus glacialoides) are more likely to be absent from the nesting cliff one year after their first successful breeding attempt than on later occasions. Ollason and Dunnet (1988) found that intermittent breeding was more frequent early in the breeding life of Atlantic Fulmars (F. glacialis). However, no similar effect was found in Wandering Albatrosses (Diomedea exulans), which nest only every second year (Weimerskirch 1992), or in Snow Petrels (Pagodroma nivea; Weimerskirch pers. comm.).

The most interesting finding from our analyses is that the reduction in the recapture rate after first-time successful breeding is highly influenced by the age at which birds breed successfully for the first time. In our sample of successful two-year-old first-time breeders, the probability of being recaptured the next year is only $55 \%$ of that of their subsequent breeding attempts, and this reduction is highly different from the reduction in recapture rates of older birds detected for the first time as successful breeders. The sample of two-year-olds contains no birds that could have nested in a previous year, since no yearling breeders have been discovered at the La Perouse Bay colony in 22 years of study.

Cooke and Rockwell (1988) found that most 
geese enter the breeding population as two- or three-year-olds. We have shown above that successful two-year-olds have a much lower chance of success in the following year, and the majority (ca. 68\%) of the birds first detected as threeyear-old breeders in fact are breeding successfully for the first time. In this sample, we found no evidence for a reduction in recapture rate after the first encounter. We did, however, detect an effect of first-time breeding when we examined the much larger data set of all birds first recaptured at three years of age or older, suggesting that the lack of effect in three-yearolds may be partly a result of the smaller sample size; there are only 792 birds in this sample against 2,004 in the sample of three-year-old and older birds. Alternatively, there may be some heterogeneity in recapture rates when birds seen for the first time at relatively advanced ages are included. Despite this caveat, the consequences of first-time breeding are dramatically different depending on the age at which the bird enters the breeding population. Such a finding has important implications in terms of life-history theory. If the consequences of first-time breeding are independent of the age of first-time breeding, the highest lifetime reproductive success is expected to accrue to those birds that enter the breeding population at the earliest age. Such are the expectations of the constraint hypothesis, and most published data derived from long-term studies of birds are consistent with this hypothesis.

Lifetime-reproductive-success calculations suggest that, because of the reduced probability of nesting successfully the following year, birds that start breeding at age 2 do not have a significantly higher expected production of goslings than birds that start at age 3 . Due to risk of mortality between years 2 and 3 , it is probably still more advantageous for a bird to start breeding at age 2 rather than at age 3 . The data, then, favor the constraint hypothesis over the restraint hypothesis, even though the advantages of nesting as a two-year-old are much less than was previously believed. This suggests that, if there were genetic variation in terms of the character "age of first breeding," selection would be directional for breeding earlier in life if resources were available. This leads to the idea that resources limit early nesting, and that only the highest-quality birds should nest as twoyear-olds, because of the risk of failure the next year. We imagine that the heritability of the character "age of first breeding" would be low and that most of the differences among birds would be nongenetic. Limitation of resources, or the ability of individuals to utilize them adequately, appears to be the main reason why delayed maturity occurs in Lesser Snow Geese.

Associated with this gradual acquisition of breeding status are several other improvements in components of fitness during the first few years of life. Increased clutch size with age has been demonstrated in most species of birds in which the phenomenon has been investigated (Finney and Cooke 1978). Usually, this phenomenon has been described as a feature of the population, but Hamann and Cooke (1987) were able to show that the clutch sizes of individual Lesser Snow Geese increased with age up to age 4. Nest and brood survival also increase up to age 4 or 5 (Rockwell et al. 1993). At the proximate level, these findings suggest that individuals become more efficient as breeders as they age, either through some physiological maturation or due to some learned process. Our findings illustrate the importance of measuring as many components of fitness under field conditions as possible. Experimental manipulations cannot compensate for this when the relative reproductive performances of different segments in the population are to be assessed. Most measures of lifetime reproductive success may be flawed if they fail to take into account more subtle interdependencies of fitness components, such as the one documented in this paper.

\section{ACKNOWLEDGMENTS}

To all those who braved polar bears and mosquitoes to band the geese used in this analysis, we give our thanks. CNRS provided hospitality to F.C. during his sabbatical year. We thank R. F. Rockwell for providing the data used in lifetime-reproductive-success calculations and for useful comments on the paper. Several granting agencies have helped to fund the research, including the Natural Science and Engineering Research Council of Canada, Canadian Wildlife Service, Mississippi and Central Flyway Councils, Ducks Unlimited Inc., Ducks Unlimited Canada, Department of Indian and Northern Affairs, and Manitoba Department of Natural Resources.

\section{LITERATURE CITED}

ABrahaM, K. F. 1980. Moult migration of Lesser Snow Geese. Wildfowl 31:89-93.

BurnhaM, K. P., D. R. Anderson, G. C. White, C. 
BrownIE, AND K. H. Pollock. 1987. Design and analysis methods for fish survival experiments based on release recapture. Am. Fisheries Monogr. No. 5.

Clobert, J., J.-D. Lebreton, D. Allaine, AND J.-M. GAILlARD. 1994. The estimation of age-specific breeding probabilities from recaptures or resightings in vertebrate populations. II. Longitudinal models. Biometrics 50:375-387.

COOCH, E. G., D. B. LANK, R. F. ROCKWELl, AND F. COOKE. 1989. Long-term decline in fecundity in a Snow Goose population: Evidence for densitydependence? J. Anim. Ecol. 58:711-726.

COOKE, F. 1987. Lesser Snow Goose: A long-term population study. Pages 407-432 in Avian genetics (F. Cooke and P. A. Buckley, Eds.). Academic Press, London.

COOKE, F., M. A. Bousfield, AND A. SAdura. 1981. Mate change and reproductive success in Lesser Snow Geese. Condor 83:322-327.

COOKe, F., C. D. Macinnes, AND J. P. PrevetT. 1975. Gene flow between breeding populations of Lesser Snow Geese. Auk 93:493-510.

COOKE, F., AND R. F. ROCKWELl. 1988. Reproductive success in Snow Geese. Pages 237-250 in Reproductive success (T. H. Clutton-Brock, Ed.). Univ. Chicago Press, Chicago.

CORMACK, R. M. 1972. The logic of capture-recapture estimates. Biometrics 28:337-343.

$\rightarrow$ Curio, E. 1983. Why do young birds reproduce less well? Ibis 125:400-404.

FINNEY, G. H., AND F. COOKE. 1978. Reproductive habits in the Snow Goose: The influence of female age. Condor 80:147-158.

FRANCIS, C. M., AND F. COOKE. 1993. A comparison of survival rate estimates from live recaptures and dead recoveries of Lesser Snow Geese. Pages 169-183 in Marked individuals in the study of bird population (J.-D. Lebreton and P. M. North, Eds.). Birkhaüser Verlag, Basel, Switzerland.

Francis, C. M., M. H. RICHARDS, F. COOKE, AND R. F. ROCKWELL. 1993. Changes in survival rates of Lesser Snow Geese with age and breeding status. Auk 109:731-747.

GuSTAFSSON, L. 1990. Life history trade-offs and optimal clutch size in relation to age in the Collared Flycatcher. Pages 235-245 in Population biology of passerine birds: An integrated approach (J. Blondel, A. Gosler, J.-D. Lebreton, and R. McCleery, Eds.). NATO ASI Series, Series G: Ecological sciences, vol. 24. Springer Verlag, Berlin.

$\rightarrow$ HAMANN, J., AND F. COOKE. 1987. Age effects on clutch size and laying dates of individual females in Lesser Snow Geese. Ibis 129:527-532.

Lebreton, J.-D., K. P. BurnhaM, J. Clobert, AND D. R. ANDERSON. 1992. Modeling survival and testing biological hypotheses using marked animals: A unified approach with case studies. Ecol. Monogr. 62:67-118.
LEBRETON, J.-D., A.-M. RebOULET, AND G. BANCO. 1993. An overview of software for terrestrial vertebrate population dynamics. Pages 357-372 in Marked individuals in the study of bird population (J.D. Lebreton and P. M. North, Eds.). Birkhaüser Verlag, Basel, Switzerland.

NEWTON, I. 1988. Age and reproduction in the Sparrowhawk. Pages 201-219 in Reproductive success (T. H. Clutton-Brock, Ed.). Univ. Chicago Press, Chicago.

NuR, N. 1990. The cost of reproduction in birds: Evaluating the evidence from manipulative and non-manipulative studies. Pages 281-296 in Population biology of passerine birds: An integrated approach (J. Blondel, A. Gosler, J.-D. Lebreton, and R. McCleery, Eds.). NATO ASI Series, Series G: Ecological sciences, vol. 24, Springer Verlag, Berlin.

Ollason, J. C., AND G. M. DunNET. 1988. Variation in breeding success in Fulmars. Pages 263-278 in Reproductive success (T. H. Clutton-Brock, Ed.). Univ. Chicago Press, Chicago.

Pollock, K. H. 1975. A $k$-sample tag-recapture model allowing for unequal survival and catchability. Biometrika 62:577-583.

Pollock, K. H., J. D. Nichols, C. BROWNIE, AND J. E. HiNES. 1990. Statistical inference for capturerecapture experiments. Wildl. Monogr. 107.

PraDEL, R. 1993. Flexibility in survival analysis from recapture data: Handling trap-dependence. Pages 29-37 in Marked individuals in the study of bird population (J.-D. Lebreton and P. M. North, Eds.). Birkhaüser Verlag, Basel, Switzerland.

Pradel, R., J. Clobert, AND J.-D. Lebreton. 1990. Recent developments for the analysis of capturerecapture multiple data sets. An example concerning two Blue Tit populations. Ring 13:193204.

REZNICK, D. 1985. Cost of reproduction: An evaluation of the empirical evidence. Oikos 44:257267.

RoBSON, D. S. 1969. Mark-recapture methods for population estimation. Pages 120-140 in New developments in survey sampling (N. L. Johnson and $H$. Smith, Eds.). Wiley, New York.

ROCKWELl, R. F., E. G. COOCH, C. B. THOMPSON, AND F. COOKE. 1993. Age and reproductive success in female Lesser Snow Geese: Experience, senescence and the cost of philopatry. J. Anim. Ecol. 62:323-333.

SEBER, G. A. F. 1982. The estimation of animal abundance and related parameters, 2nd ed. Charles Griffin \& Company, London.

VAN NoORdwiJK, A. J., AND G. DE JoNG. 1986. Acquisition and allocation of resources: Their influence on variation in life history tactics. Am. Nat. 128:137-142.

WEIMERSKIRCH, H. 1990. The influence of age and experience on breeding performance of the Ant- 
arctic Fulmar (Fulmarus glacialoides). J. Anim. Ecol. 59:867-875.

WEIMERSKIRCH, H. 1992. Reproductive effort in longlived birds: Age-specific patterns of condition, reproduction and survival in the Wandering $\mathrm{Al}$ batross. Oikos 64:464-473.

Williams, G. C. 1966. Natural selection, costs of reproduction and a refinement of Lack's principle. Am. Nat. 100:687-690.

WOOlleR, R. D., AND J. C. Coulson. 1977. Factors affecting the age of first breeding in the Kittiwake Rissa tridactyla. Ibis 119:339-349.

\section{APPENDIX \\ Goodness-of-fit test for model $\phi_{t * a 2}, p_{t * a 2}$}

The model denoted in this paper as $\left(\phi_{t, F}, p_{t \cdot F}\right)$ can be viewed as a model with two age classes, where "age" means "time elapsed since first capture." The first age class considers the first time interval after banding (for $\phi$ ), or the first recapture occasion (for $p$ ). The second age class considers all further intervals or occasions. This model is denoted as $\left(\phi_{t \cdot a 2}, p_{t \cdot a 2}\right)$. It is a particular case of Pollock's (1975) general agedependent model (see also Robson 1969, Cormack 1972:341). This model is very useful in many cases (e.g. transient animals [Pradel et al. unpubl. manuscript] animals banded as young [Clobert et al. 1994]).
Among the most-common computer programs for analysis of capture-recapture data (see Lebreton et al. 1993), we could not find any readily available goodness-of-fit test for this model. In particular, the tests provided by JOLLYAGE (Pollock et al. 1990) are inadequate.

However, testing the fit of a preliminary model is critical to all further analyses, since the distribution of statistics used in model selection depends on the fit of the model used as a starting point (Lebreton et al. 1992). A complete goodness-of-fit test for this model is based on a splitting of each capture history as proposed by Clobert et al. (1994); each is split into two fictitious recapture histories (see Fig. 4). The data set is transformed into two fictitious data subsets, the first containing records of the first or of the two first captures of all individuals, and the second containing records of all subsequent occasions. The goodness-offit test for model $\left(\phi_{t \cdot a 2}, p_{t \cdot a 2}\right)$ is then made up of three components:

(1) The first component is a goodness-of-fit test of model $\left(\phi_{t * a 2}, p_{t * a 2}\right)$ for the part of the data concerning just the first recapture of each individual (parameter structure for this model is given in left half of Table 2). One easily can prove that the fit of a model incorporating parameters as in Table 2 to this data subset is tested by Test $2 . \mathrm{Cm}$ (implemented in program RELEASE; Pradel 1993). The corresponding chi-square statistic is noted as $C 1$, with $d f 1$ degrees of freedom.

Original data set

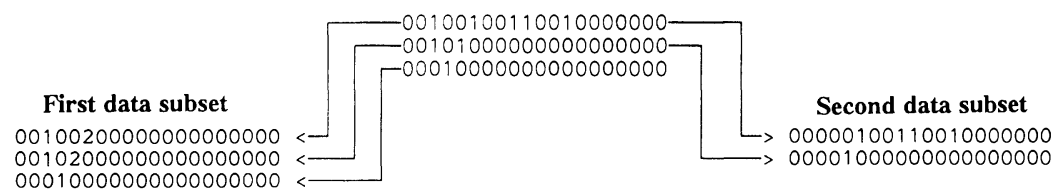

Fig. 4. Splitting capture-recapture data set into two fictitious subsets according to first recapture of individuals. Each row represents an individual capture history across years, coded as: (0) animal not captured; (1) animal captured and released; (2) animal captured and removed from data set.

TABLE 2. Parameter structure for first model (with $k=5$ capture occasions) fitted on two subsets described in Figure 4. Parameters marked with asterisk $\left(^{*}\right)$ correspond to first age class.

\begin{tabular}{|c|c|c|c|c|c|c|c|c|c|c|}
\hline \multirow[b]{2}{*}{ Cohort } & \multicolumn{5}{|c|}{$\begin{array}{l}\text { First pseudogroup } \\
\text { occasion no. }\end{array}$} & \multicolumn{5}{|c|}{$\begin{array}{l}\text { Second pseudogroup } \\
\text { occasion no. }\end{array}$} \\
\hline & 1 & 2 & 3 & 4 & 5 & 1 & 2 & 3 & 4 & 5 \\
\hline \multicolumn{11}{|c|}{ Survival parameters } \\
\hline $\begin{array}{l}1 \\
2 \\
3 \\
4\end{array}$ & & $\Phi_{1}^{*}$ & $\begin{array}{l}\Phi_{2} \\
\Phi_{2}^{*}\end{array}$ & $\begin{array}{l}\Phi_{3} \\
\Phi_{3} \\
\Phi_{3}{ }^{*}\end{array}$ & $\begin{array}{l}\Phi_{4} \\
\Phi_{4} \\
\Phi_{4} \\
\Phi_{4}{ }^{*}\end{array}$ & & & $\Phi_{2}{ }^{\prime}$ & $\begin{array}{l}\Phi_{3}{ }^{\prime} \\
\Phi_{3}{ }^{\prime}\end{array}$ & $\begin{array}{l}\Phi_{4} \\
\Phi_{4} \\
\Phi_{4}\end{array}$ \\
\hline \multicolumn{11}{|c|}{ Capture parameters } \\
\hline $\begin{array}{l}1 \\
2 \\
3 \\
4\end{array}$ & & $p_{2}^{*}$ & $\begin{array}{l}p_{3} \\
p_{3}{ }^{*}\end{array}$ & $\begin{array}{l}p_{4} \\
p_{4} \\
p_{4}{ }^{*}\end{array}$ & $\begin{array}{l}p_{5} \\
p_{5} \\
p_{5} \\
p_{5}\end{array}$ & & & $p_{3}{ }^{\prime}$ & $\begin{array}{l}p_{4}^{\prime} \\
p_{4}^{\prime}\end{array}$ & $\begin{array}{l}p_{5} \\
p_{5}^{\prime} \\
p_{5}\end{array}$ \\
\hline
\end{tabular}


TABLE 3. Three components of goodness-of-fit test for model $\left(\phi_{t \cdot a 2}, p_{t \cdot a 2}\right)$ for all birds.

\begin{tabular}{cccc}
\hline \hline$i$ & $\mathrm{C}_{i}$ & $\mathrm{df}_{i}$ & $P$ \\
\hline 1 & 39.98 & 39 & 0.43 \\
2 & 61.04 & 72 & 0.82 \\
3 & 18.76 & 35 & 0.99 \\
Total & 119.78 & 146 & 0.94 \\
\hline
\end{tabular}

(2) The goodness-of-fit test of a model as in Table 2 (right) for the second data subset is a standard goodness-of-fit test of model $\left(\phi_{t}, p_{t}\right)$, since all pseudoindividuals in this group are beyond age class 1 . Tests
2 and 3 in program RELEASE (Burnham et al. 1987) provide the corresponding chi-square statistic, noted C2, with $d f 2$ degrees of freedom.

(3) The third needed component, $C 3$, corresponds to a test of $\mathrm{H}_{0}: p_{i}=p_{i}{ }^{\prime}(i=3, \ldots, k), \phi_{i}=\phi_{i}{ }^{\prime}(i=2, \ldots, k$ $-1)$. It can be obtained as a likelihood-ratio test using SURGE.

An overall goodness-of-fit statistic is the sum of the three independent chi-square statistics above. Under $\mathrm{H}_{0}, \mathrm{C} 1+\mathrm{C} 2+\mathrm{C} 3$ is distributed as $\chi_{(d f 1+d f 2+d f 3)}^{2}$. However, a close look at individual components is recommended. The results in our case are as in Table 3. 